\title{
Peran Komitmen Organisasi dalam Menurunkan Pengaruh Negatif Turnover Intention terhadap Kinerja Karyawan (Studi kasus: GroupM Indonesia)
}

\section{The Role of Organizational Commitment to Decrease Negative Effect of Turnover Intention on Employee Performance (Case Study: GroupM Indonesia)}

\author{
Aria Andriyadi ${ }^{1}$, Anggraini Sukmawati ${ }^{2 *}$, U. Dyah Syafitri ${ }^{3}$ \\ ${ }^{1)}$ Program Studi Ilmu Manajemen, Departemen Manajemen, Fakultas Ekonomi dan Manajemen, Institut Pertanian Bogor, Kampus \\ IPB Darmaga Bogor 16680 \\ ${ }^{2)}$ Departemen Manajemen, Fakultas Ekonomi dan Manajemen, Institut Pertanian Bogor, Kampus IPB Darmaga Bogor 16680 \\ ${ }^{3}$ Departemen Statistika, Fakultas Matematika dan Ilmu Pengetahuan Alam, Institut Pertanian Bogor, Kampus IPB Darmaga Bogor \\ 16680
}

\begin{abstract}
Information about the factors that influence turnover intention is needed by managerial in providing strategic steps to overcome the negative effects of high turnover intention. This study aims to analyze the effect of turnover intention on employee performance with organizational commitment as a moderator variable. The sampling method used was the proportionate stratified random sampling technique. The research data used respondents' perceptions of the variables, then analyzed using Structural Equation Modeling-Partial Least Square (SEM-PLS) method. The results of this study indicate that turnover intention has a negative relation toward employee performance and commitment, although not significant. This condition can occur because of tugging to get high-performing talents in the service industry. This condition is triggered by the increasingly open competition in the world of work so that employees are aware of having to create a positive impression for the company to be left, which will usually be a recommendation to the next destination company. High organizational commitment is an important factor in improving employee performance. High organizational commitment will reduce the desire of employees to leave a company (turnover intention) and reduce the negative influence on employee performance, so that despite high turnover intention, employee performance is remaining high. This happens especially in service companies whose main capital is human resources.
\end{abstract}

Keywords: human resource management, partial least quare, organizational behavior, service company, structural equation modeling,

\begin{abstract}
ABSTRAK
Informasi mengenai faktor-faktor yang memengaruhi turnover intention sangat diperlukan oleh manajerial dalam memberikan langkah-langkah strategis untuk mengatasi efek negatif tingginya turnover intention. Penelitian ini bertujuan menganalisis pengaruh turnover intention terhadap kinerja karyawan dengan komitmen organisasi sebagai variabel moderator. Penarikan sampel yang digunakan adalah teknik proportionate stratified random sampling. Data penelitian ini menggunakan persepsi responden terhadap variabel-variabel yang diteliti, kemudian dianalisis menggunakan metode Structural Equation Modeling-Partial Least Square (SEM-PLS). Hasil penelitian ini menunjukkan bahwa turnover intention memiliki arah hubungan negatif terhadap kinerja karyawan dan komitmen meskipun tidak signifikan. Kondisi tersebut bisa saja terjadi karena tarik-ulur untuk mendapatkan talenta-talenta yang berkinerja tinggi di industri jasa. Kondisi ini dipicu semakin terbukanya persaingan di dunia kerja sehingga para karyawan sadar harus menciptakan kesan positif bagi perusahaan yang akan ditinggalkan yang biasanya akan menjadi rekomendasi ke perusahaan tujuannya nanti. Komitmen organisasi menjadi faktor penting dalam meningkatkan kinerja karyawan. Komitmen organisasi yang tinggi akan menurunkan keinginan karyawan untuk keluar dari suatu perusahaan (turnover intention) dan mengurangi pengaruh negatif terhadap kinerja karyawan, sehingga meskipun turnover intention tinggi, kinerja karyawan tetap tinggi. Hal ini terjadi terutama di perusahaan jasa yang modal utamanya adalah sumber daya manusia.
\end{abstract}

Kata Kunci: manajemen sumber daya manusia, partial least quare, perilaku organisasi, perusahaan jasa, structural equation modeling,

*Corresponding author

Alamat e-mail: anggrainism@apps.ipb.ac.id 


\section{PENDAHULUAN}

Pentingnya karyawan sebagai faktor keberhasilan perusahaan, maka diperlukan komitmen organisasi untuk meningkatkan kontribusi karyawan pada perusahaan tersebut. Jika kepuasan karyawan hanya mendorong seorang karyawan untuk memikirkan kesuksesan dirinya sendiri, sedangkan keterlekatan karyawan akan mampu mendorong karyawan untuk melakukan pekerjaannya secara luar biasa. Dengan demikian mereka memiliki komitmen terhadap perusahaan bahkan lebih dari ekspektasi perusahaan.

Perusahaan perlu meningkatkan produk, pelayanan, strategi dan teknologi serta alur cashflow yang baik di era kompetisi bisnis yang makin ketat. Faktanya, tidak sedikit perusahaan yang melewatkan faktor lain yang juga sangat penting dalam menentukan keberhasilan, yaitu loyalitas tenaga kerja. Karyawan dalam sebuah perusahaan merupakan nilai dan kekuatan jangka panjang yang menentukan terciptanya keuntungan kompetitif yang berkelanjutan seperti Return of Investment (ROI) hingga pada perolehan laba atas investasi. Terutama pada perusahaan yang bergerak di bidang jasa, karyawan merupakan salah satu faktor penting dalam keberlanjutan perusahaan sesuai dengan yang disampaikan oleh Gea (2014) bahwa manusia adalah komponen utama dalam sebuah bisnis. Keahlian dan pengalaman tertentu masih menjadi fokus dan perhatian banyak perusahaan di Indonesia. Alasannya, persaingan bisnis yang makin ketat dan perkembangan teknologi penunjangnya menuntut ketersediaan sumber daya manusia dengan keterampilan dan pengalaman kerja yang sesuai dengan perkembangan tersebut. Oleh karena itu, nilai turnover intention perlu diamati untuk menilai sejauh mana karyawan ada rasa ingin keluar dari perusahaan dan manajerial bisa bertindak untuk menanggulangi hal tersebut terutama untuk karyawan yang memiliki kinerja tinggi agar tetap setia terhadap perusahaan.

Mengingat pentingnya karyawan sebagai faktor keberhasilan perusahaan, maka diperlukan komitmen terhadap karyawan untuk meningkatkan loyalitas karyawan pada perusahaan tersebut. Karyawan yang terikat merupakan tujuan yang paling pokok dalam pengembangan sumber daya manusia di dalam suatu perusahaan. Jika kepuasan karyawan hanya mendorong seorang karyawan untuk memikirkan kesuksesan dirinya sendiri, komitmen akan mampu mendorong karyawan untuk melakukan pekerjaannya secara luar biasa, bahkan lebih dari ekspektasi perusahaan. Komitmen membuat karyawan tidak hanya mendorong karyawan untuk memikirkan kesuksesan dirinya sendiri, tapi juga kesuksesan perusahaan tempatnya bekerja. Komitmen yang tinggi diharapkan berpengaruh negatif terhadap nilai turnover dalam rangka mempertahankan karyawan yang berkinerja baik. Komitmen yang tinggi akan membuat rasa keinginan karyawan untuk keluar dari perusahaan tersebut atau yang biasa disebut dengan turnover intention semakin kecil dan kinerja karyawan semakin tinggi terutama di perusahaan jasa yang modal utamanya adalah sumber daya manusia.

Penelitian ini bertujuan untuk melihat pengaruh turnover intention terhadap komitmen dan kinerja karyawan GroupM sehingga hasilnya akan menjadi saran kepada manajerial. Perusahaan yang diteliti merupakan perusahaan jasa yang bergerak di bidang media periklanan. Berkembangnya industri kreatif media dan meningkatnya persaingan di industri tersebut menuntut perusahaan untuk terus bergerak maju salah satunya dalam hal sumberdaya manusia. Kondisi yang justru terjadi adalah tingkat turnover yang cukup tinggi. Informasi mengenai turnover intention sangat diperlukan oleh manajerial dalam memberikan langkah-langkah strategis. Selain itu, kondisi tersebut menuntut perusahaan sebagai organisasi harus merespon dengan cepat untuk menangani efek negatif tingginya turnover. Peneliti berharap hasil penelitian ini dapat memberikan implikasi manajerial terhadap GroupM dan perusahaan sebidang untuk meningkatkan kinerja sumber daya manusia yang dimiliki yang berdampak positif terhadap performa perusahaan.

\section{METODE PENELITIAN}

Populasi meliputi seluruh karyawan yang berjumlah sekitar 452 orang. Sumber data yang digunakan dalam penelitian ini adalah data primer dan sekunder. Data primer diperoleh langsung dari responden melalui kuesioner terstruktur yang disebarkan kepada responden yaitu 83

Jurnal Manajemen dan Organisasi (JMO), Vol. 9 No. 2, Agustus 2018, Hal. 81-90 
karyawan. Data sekunder yang digunakan oleh peneliti adalah data yang diperoleh melalui kajian kepustakaan maupun data yang diperoleh dari organisasi.

Populasi merupakan kumpulan lengkap dari objek pengamatan yang menjadi pusat perhatian penelitian. Total tersebut diambil sampel untuk dilakukan pengamatan dalam penelitian ini. Sampel adalah suatu prosedur yang hanya mengamati sebagian objek pengamatan. Penentuan sampel yang dibutuhkan apabila populasi diketahui dengan menggunakan rumus Slovin.

$\mathrm{n}=\mathrm{N} /((\mathrm{N} \cdot \mathrm{d} 2)+1)$.

Dimana: $\mathrm{n}=$ Ukuran sampel

$\mathrm{N}=$ Ukuran populasi

$\mathrm{d}^{2}=$ Tingkat kesalahan dalam penarikan sampel $(10 \%)$

$1=$ Konstanta

Berdasarkan rumus dan teori diatas, jumlah sampel yang digunakan dalam penelitian dengan ukuran populasi 452 orang dapat dihitung sebagai berikut:

$\mathrm{n}=\frac{452}{[452.0 .01]+1}$

$\mathrm{n}=81,88 \approx 82$ responden

Penarikan sampel yang digunakan adalah teknik probability sampling dengan metode proportionate stratified random sampling, yaitu teknik yang digunakan bila populasi mempunyai anggota atau unsur yang tidak homogen dan berstrata secara proporsional (Sugiyono 2010). Metode tersebut bertujuan untuk mengurangi ragam dari nilai dugaan sehingga akan menghasilkan nilai dugaan yang memiliki ketepatan relatif tinggi. Rumus yang digunakan untuk menghitung sampel dalam setiap unit kerja adalah:

$\mathrm{n}_{\mathrm{i}}=\frac{\mathrm{Ni}}{\mathrm{N}} \mathrm{x}$

Keterangan:

$\mathrm{n}_{\mathrm{i}}=$ Anggota sampel pada proporsi ke $\mathrm{i}$

$\mathrm{N}_{\mathrm{i}}=$ Populasi ke $\mathrm{i}$

$\mathrm{n}=$ Sampel yang diambil daam penelitian

$\mathrm{N}=$ Populasi total

Penelitian ini menggunakan 100 responden yaitu 18 lebih banyak dari minimal jumlah responden yang disarankan. Penentuan jumlah sampel menggunakan teori dari Ferdinand (2002) yang dikutip oleh Sanusi (2014) yang menyatakan bahwa Jumlah sampel adalah jumlah indikator variabel bentukan yang dikali dengan 5 sampai dengan 10. Penarikan sampel yang digunakan adalah teknik probability sampling dengan metode proportionate stratified random sampling, yaitu teknik yang digunakan bila populasi mempunyai anggota atau unsur yang tidak homogen dan berstrata secara proporsional (Sugiyono 2010). Metode tersebut bertujuan untuk mengurangi ragam dari nilai dugaan sehingga akan menghasilkan nilai dugaan yang memiliki ketepatan relatif tinggi. Rumus yang digunakan untuk menghitung sampel dalam setiap unit kerja adalah:

$\mathrm{ni}=\mathrm{Ni} / \mathrm{N} \times \mathrm{n}$.

Keterangan:

$\mathrm{ni}=$ anggota sampel pada proporsi ke $\mathrm{i}$

$\mathrm{Ni}=$ populasi $\mathrm{ke} \mathrm{i}$

$\mathrm{n}=$ sampel yang diambil dalam penelitian

$\mathrm{N}$ = populasi total

Metode statistik deskriptif digunakan untuk menganalisis data dengan cara

Jurnal Manajemen dan Organisasi (JMO), Vol. 9 No. 2 , Agustus 2018, Hal. $81-90$ mendeskriptifkan atau menggambarkan data yang terkumpul sebagaimana adanya tanpa bermaksud membuat kesimpulan yang berlaku umum atau generalisasi (Sanusi 2014). Metode berikutnya dengan menggunakan Structural Equation Modelling (SEM). Adapun SEM adalah sebuah metode statistika untuk menilai suatu model dengan melihat adanya hubungan sebab akibat antar variabel yang diteliti. Data yang terkumpul selanjutnya dianalisis dengan 
menggunakan model persamaan struktural dengan menggunakan software Partial Least Square (PLS).

Penelitian ini terdiri atas variabel-variabel, yaitu turnover intention, komitmen organisasi, dan kinerja karyawan. Pada gambar 1 dibawah ini adalah path diagram yang merupakan model awal untuk mendeskripsikan suatu hubungan antara variabel laten eksogen dengan endogen.

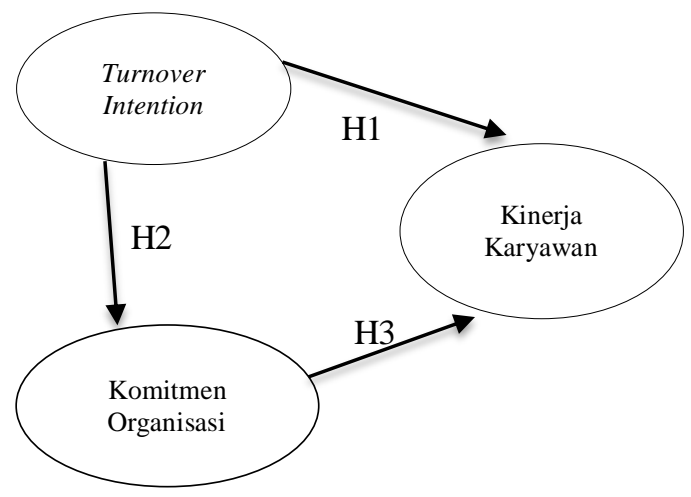

Gambar 1. Path Diagram pengaruh Turnover Intention dan Komitmen terhadap Kinerja Karyawan.

Hipotesis pada penelitian ini adalah sebagai berikut:

$\mathrm{H} 1$; turnover intention berpengaruh negatif terhadap kinerja karyawan

$\mathrm{H} 2$; turnover intention berpengaruh negatif terhadap komitmen organisasi

H3; komitmen organisasi berpengaruh positif terhadap kinerja karyawan

\section{HASIL DAN PEMBAHASAN}

Penelitian ini mengukur turnover intention, kineja karyawan dan komitmen organisasi sebagai persepsi responden melalui kuesioner yang disebarkan. Turnover intention diukur sejauh mana responden menilai diri mereka sendiri mengenai keingian atau hasrat ingin keluar dari perusahaan. Responden pun menilai sejauh mana persepsi mereka merasa terikat dengan perusahaan melalui variabel engagement karyawan. Selain itu, responden menilai diri mereka sendiri mengenai kinerja mereka terhadap apa yang sudah mereka kerjakan selama ini. Variabelvariabel tersebut untuk melihat peran turnover intention dan engagement karyawan terhadap kinerja karyawan.

Berawal dari cukup tingginya turnover karyawan GroupM bila dibandingkan dengan literatur, penelitian ini menganalisis turnover intention yang menurut Harnoto (2002) turnover intention adalah kadar atau intensitas keinginan untuk keluar dari perusahaan. Variable lain yang dilihat adalah persepsi kinerja karyawan. Kinerja merupakan hasil kerja secara kuantitas yang dicapai oleh seseorang karyawan dalam melaksanakan tugasnya sesuai dengan tanggung jawabnya (Mangkunegara 2000). Variabel lainnya yang diukur adalah komitmen organisasi. Komitmen organisasional adalah tingkat sampai mana seorang karyawan memihak suatu organisasi serta tujuan-tujuan dan keinginannya untuk mempertahankan keanggotaannya dalam organisasi tersebut (Robbins dan Judge 2013). Hasil akhirnya akan dilihat sejauh mana pengaruh faktor-faktor tersebut saling berpengaruh dan memberikan implikasi manajerial pada perusahaan tersebut. 


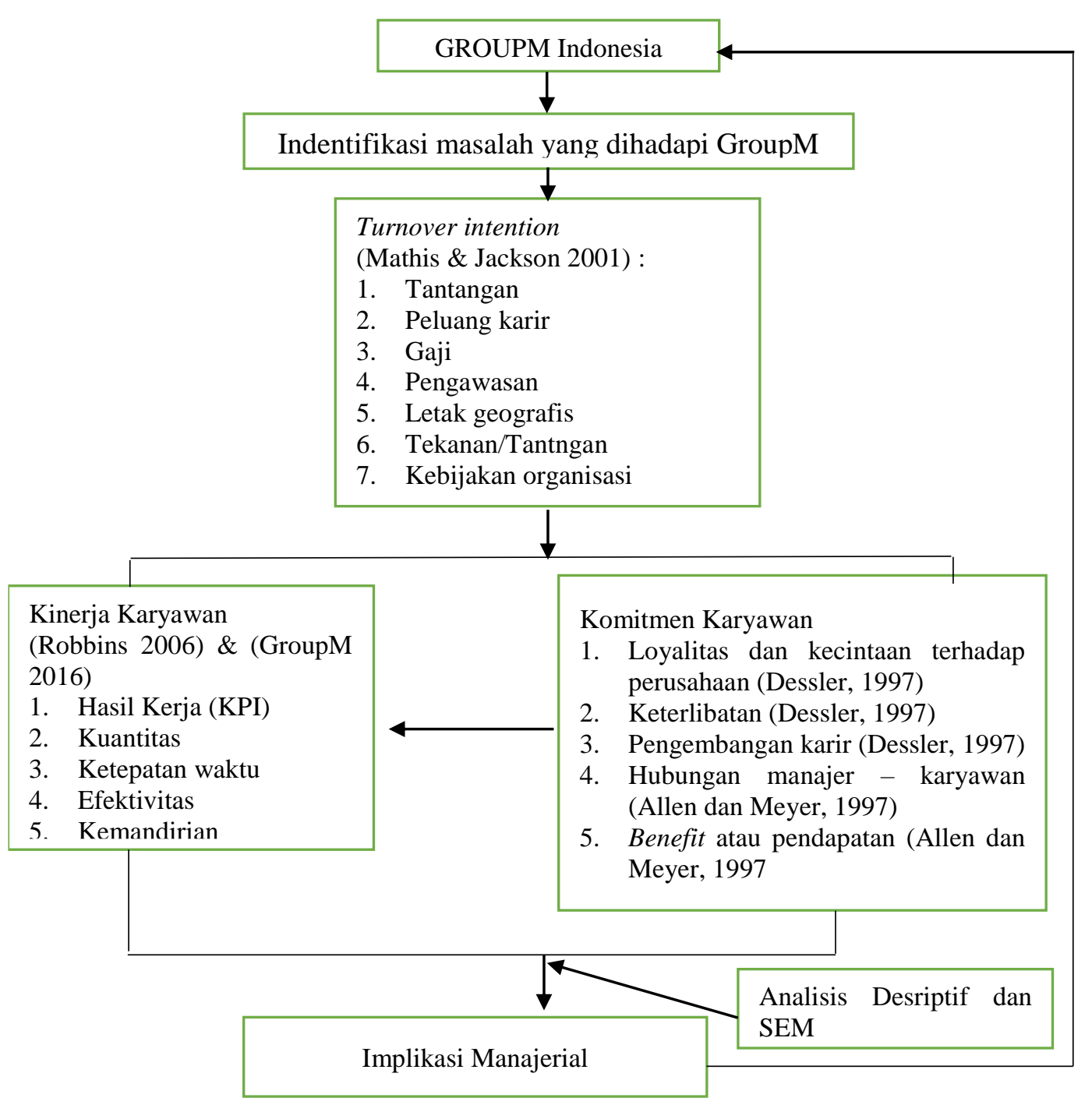

Gambar 2. Kerangka Pemikiran Penelitian

\section{Profil Responden}

Jumlah responden pada penelitian ini sebanyak 82 karyawan. Beberapa deskripsi responden didapat dari hasil kuesioner yaitu kategori jenis kelamin, usia, pendidikan terakhir, masa kerja, status jabatan dan status kewarganegaraan.

Tabel 1. Profil Responden ${ }^{\mathrm{a}}$

\begin{tabular}{clrc}
\hline No & \multicolumn{1}{c}{ Profil } & $\begin{array}{c}\text { Jumlah } \\
\text { responden }\end{array}$ & Persentase (\%) \\
\hline 1 & Jenis kelamin & 35 & \\
& Pria & 47 & 43 \\
& Wanita & & 57 \\
2 & Usia & 26 & 32 \\
& $\leq 25$ & 35 & 43 \\
& $26-30$ & 16 & 20 \\
& $31-40$ & 4 & 5 \\
& $41-50$ & & \\
3 & Pendidikan terakhir & 62 & 75 \\
& Sarjana & 21 & 25 \\
\hline
\end{tabular}




\begin{tabular}{|c|c|c|c|}
\hline No & Profil & $\begin{array}{c}\text { Jumlah } \\
\text { responden }\end{array}$ & Persentase $(\%)$ \\
\hline \multirow[t]{4}{*}{4} & Masa Kerja & & \\
\hline & $<5$ th & 42 & 51 \\
\hline & $6-10$ th & 34 & 42 \\
\hline & $11-15$ th & 6 & 7 \\
\hline \multirow[t]{6}{*}{5} & Jabatan & & \\
\hline & Executive & 28 & 34 \\
\hline & Manager & 28 & 34 \\
\hline & Group Head & 12 & 15 \\
\hline & Associate Partner & 11 & 13 \\
\hline & Client Lead & 3 & 4 \\
\hline \multirow[t]{3}{*}{6} & Status Kewarganegaraan & & \\
\hline & WNI & 74 & 90 \\
\hline & WNA & 8 & 10 \\
\hline
\end{tabular}

${ }^{2}$ Data berdasarkan hasil kusioner yang dibagikan kepada responden karyawan GroupM (2017)

Pada Tabel 1 menunjukkan profil karyawan yang dijadikan dalam penelitian ini. Berdasarkan jumlah kelamin, karyawan di GroupM sebagian besar adalah generasi millenials pada umur kurang dari 30 tahun dengan mayoritas karyawan adalah wanita. Definisi operasional untuk jabatan di GroupM untuk executive adalah jabatan yang didapat untuk karyawan yang baru masuk baik dari program managament trainee atau bagi yang tidak punya pengalaman sebelumnya. Manager bertanggungjawab untuk memonitor pekerjaan sehari-hari bawahannya, namun fenomena di GroupM tidak semua manager memiliki bawahan. Hal yang membedakan jabatan executive dan manager hanya dari segi pengalaman kerja dan benefit yand didapat. Group head bertanggung jawab untuk memonitor kategori yang menjadi tanggung jawabnya, misalkan di Mindhsare Unilever, pembagian kategori berdasarkan kategori yang ada di PT Unilever diantaranya kategori sampo, kategori sabun, kategori pasta gigi dan sebagainya. Adapun associate partner bertanggung jawab lebih besar. Dia memonitor kategori-kategori yang menjadi tanggung jawabnya. Contoh untuk di Mindshare Unilever associate partner dibagi menjadi innovasi tim, konten tim, kategory personal care, kategori non-personal care. Client Lead memiliki tugas yang lebih besar yakni memastikan seluruh kegiatan bisnis baik internal maupun hubungan dengan client berjalan dengan baik. Client lead dibagi berdasarkan perusahaan yang ditangani, misalkan client lead untuk unilever, client lead untuk indofood dan sebagainya.

Karyawan di perusahaan GroupM memiliki latar belakang budaya yang beragam karena merupakan multi national company. Pola perekrutan untuk karyawan lokal dibagi menjadi dua, yaitu pro hire dan program media master. Pro hire dilakukan biasanya untuk mencari minimal level manager yang didapat dari referensi karyawan dan situs-situs profesional seperti jobstreet dan linkedin, sedangkan untuk program media master dilakukan oleh tim Human Resources (HR) secara roadshow atau jemput bola ke kampus-kampus besar negeri di Indonesia. Karyawan di GroupM selain talenta lokal yang berasal dari berbagai penjuru Indonesia, juga berasal dari luar negeri seperti India, Afrika Selatan, Jepang, Prancis, Amerika Serikat, Singapura, Inggris dan beberapa negara lainnya. Hal ini menambah lingkungan kerja yang semakin dinamis di perusahaan ini.

\section{Pengaruh Turnover Intention dan Komitmen Organisasi terhadap Kinerja Karyawan}

Analisis model awal yang dilakukan adalah analisis model struktural. Analisis ini adalah hasil pengolahan data untuk menjawab hasil penelitian. Hubungan dan tingkat signifikansi antar variabel dapat dilihat pada gambar 2 dan 3. Gambar 3 menunjukkan model struktural dan diagram koefisien jalur tahap awal. Terdapat 7 (tujuh) variabel untuk mengukur turnover intention yaitu tantangan (TI1), peluang karir (TI2), gaji (TI3), pengawasan (TI4), letak geografis (TI5), tekanan (TI6) dan kebijakan organisasi (TI7). Terdapat 5 (lima) variabel untuk mengukur kinerja karyawan yaitu hasil kerja (K1), kuantitas (K2), ketepatan waktu (K3), efektivitas (K4) dan kemandirian (K5). Terdapat 5 (lima) variabel untuk mengukur komitmen organisasi yaitu arti perusahaan bagi pribadi (E1), keterlibatan (E2), pengembangan karir (E3), hubungan manajer -

Jurnal Manajemen dan Organisasi (JMO),

Vol. 9 No. 2, Agustus 2018, Hal. 81-90 
karyawan (E4) dan benefit (E5). Adapun hasil kecocokan model struktur dan koefisien jalur ditunjukkan pada Tabel 2.

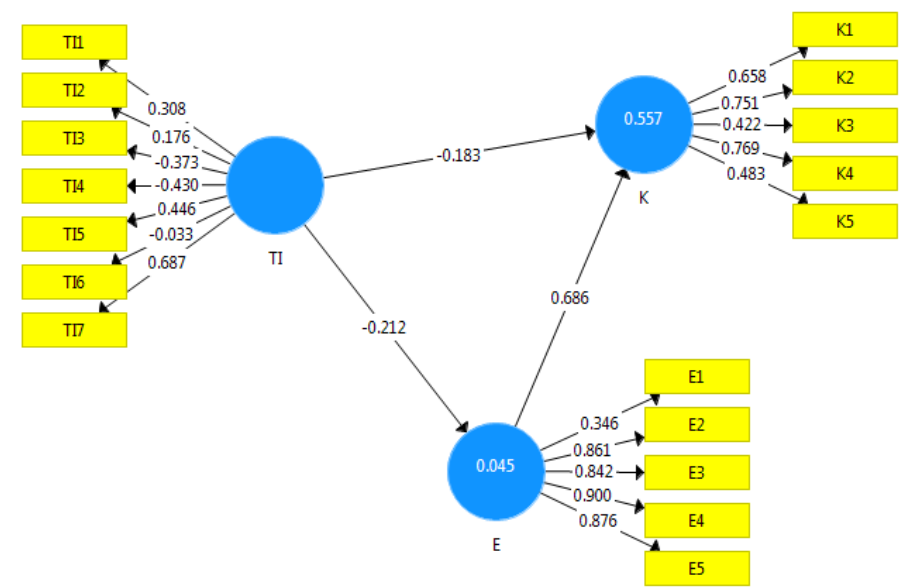

Gambar 3. Kecocokan model struktural, diagram koefisien jalur

Keterangan :

$\begin{array}{ll}\mathrm{TI} & =\text { Turnover Intention } \\ \mathrm{K} & =\text { Kinerja } \\ \mathrm{E} & =\text { Komitmen }\end{array}$

TI1,2,3,4,5,6,7 = Turnover intention variabel ke- 1,2,3,4,5,6,7

$\mathrm{K} 1,2,3,4,5=$ Kinerja variabel ke-1,2,3,4,5

$\mathrm{E} 1,2,3,4,5=$ Komitmen variabel ke- $1,2,3,4,5$

Tabel 2. Hasil Kecocokan model struktur dan koefisien jalur ${ }^{\mathrm{a}}$

\begin{tabular}{lccc}
\hline \multicolumn{1}{c}{ Variabel } & Composite reliability & AVE & R-square \\
\hline Komitmen & 0,89 & 0,63 & 0,05 \\
Kinerja & 0,76 & 0,40 & 0,56 \\
Turnover intention & 0,09 & 0,16 & 0,00 \\
\hline
\end{tabular}

${ }^{a}$ Data berdasarkan hasil running SEM PLS

Tabel 2 menunjukkan bahwa Nilai AVE untuk variabel K dan TI masih ada yang kurang dari 0,5, sehingga perlu dilakukan perbaikan yaitu menghilangkan indikator yang nilai loading factornya dibawah 0,4, yaitu TI1, TI2, TI3, TI4, TI6, dan E1.

Jurnal Manajemen dan Organisasi (JMO),

Vol. 9 No. 2, Agustus 2018, Hal. 81-90

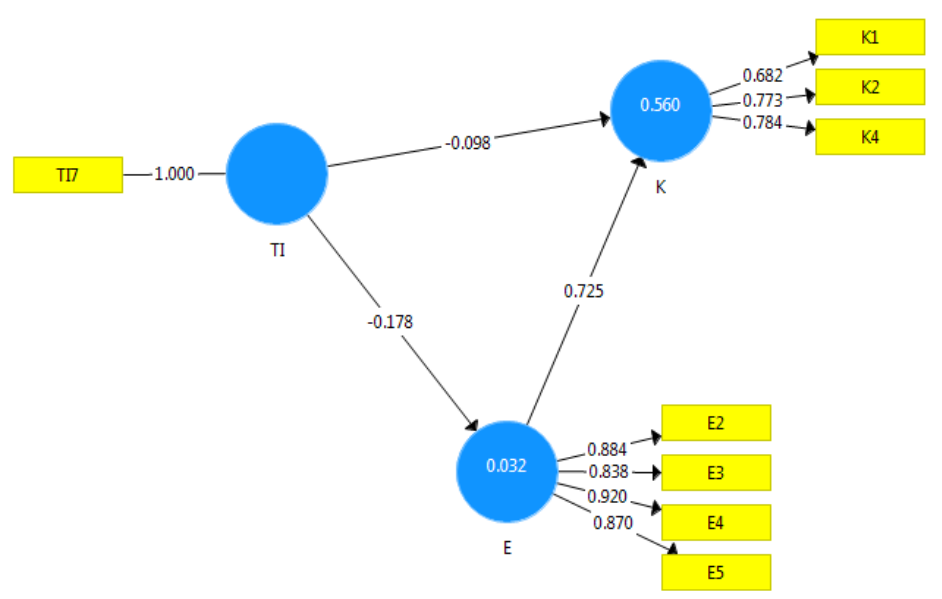

Gambar 4. Kecocokan model struktural, diagram koefisien jalur akhir 
Keterangan :

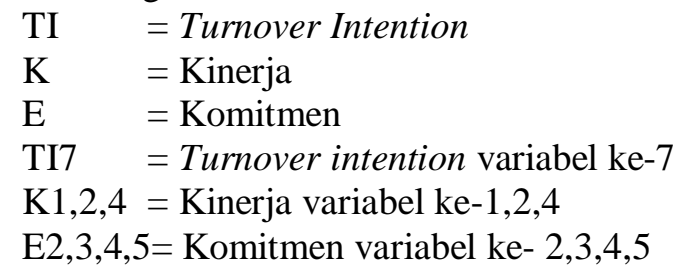

Setelah dilakukan beberapa tahap, didapatkan model struktural akhir ditunjukkan pada Gambar 3 yang mengeliminasi beberapa variabel dan hanya menyisakan TI7, KI1, KI2, KI4, E2, E3, E4, dan E5 yang ditunjukkan pada Gambar 4. Adapun hasil kecocokan model struktur dan koefisien jalur akhir ditunjukkan pada Tabel 3.

Tabel 3. Hasil Kecocokan model struktur dan koefisien jalur akhir ${ }^{\mathrm{a}}$

\begin{tabular}{lccc}
\multicolumn{1}{c}{ Variabel } & Composite reliability & AVE & R-square \\
\hline Komitmen & 0,93 & 0,77 & 0,03 \\
Kinerja & 0,79 & 0,56 & 0,56 \\
Turnover intention & 1,00 & 1,00 & 0,00 \\
\hline${ }^{a}$ Data berdasarkan hasil dari running & SEM PLS & &
\end{tabular}

Model SEM yang diuji sudah reliabel karena nilai composite reliability sudah diatas 0,7 dan sudah valid karena nilai loading factor sudah lebih dari 0,6. Variabel juga sudah memiliki kontribusi yang baik karena nilai AVE semuanya sudah diatas 0,5 (Tabel 3). Variabel pendukung yang masuk ke model akhir untuk variabel turnover intention adalah TI7 yaitu kebijakan organisasi, variabel komitmen adalah E2, E3, E4, E5 yaitu keterlibatan, pengembangan karir, hubungan manajer dan karyawan, benefit, dan variabel kinerja adalah K1, K2, K4 yaitu hasil kerja, kuantitas, efektivitas.

Hasil dari struktur model akhir ini menunjukkan bahwa hal yang paling berpengaruh terhadap turnover intention di GroupM adalah kebijakan organisasi. Karyawan di GroupM merasa engage terhadap perusahaan karena mereka merasa dilibatkan dalam hal kegiatan perusahaan. Karyawan pun meresa pengembangan karir menjadi faktor mereka merasa engage dengan perusahaan. Mereka merasa pengembangan karir di GroupM jelas. Hal itu penting karena terkait jenjang karir yang akan mereka jalani di perusahaan ini. Hubungan manajer dan karyawan di perusahaan ini pun tidak terlalu membuat karyawan merasa tertekan. Karyawan merasa hubungan manajer dan karyawan seperti keluarga atau teman dekat sehingga karyawan merasa nyaman di perusahaan ini. Selain itu, faktor penting yang membuat karyawan merasa engage dengan perusahaan adalah benefit yang diberikan. Salah satu benefit yang diberikan berupa material seperti voucher taxi untuk karyawan yang lembur, bonus, asuransi, medical reimburse, bonus loyalitas karyawan (5 tahun, 10 tahun, 15 tahun, dst), uang ucapan ulang tahun dari manajerial dan disampaikan langsung oleh CEO GroupM yang membuat mereka merasa spesial di hari spesial karyawan. Selain itu, benefit non material pun nampaknya membuat karyawan merasa engage terhadap perusahaan salah satunya seperti diberikannya cuti ulang tahun sehingga karyawan bisa merayakan ulang tahun dengan keluarga tercinta, unpaid leave selama waktu tertentu bila dibutuhkan serta cuti tambahan bagi mereka yang mencapai 5 tahun dan kelipatannya bekerja di GroupM.

Kinerja merupakan hasil yang diukur dari proses kerja karyawan. Kinerja karyawan GroupM dilakukan berkala secara setahun sekali untuk mengevaluasi agar kedepannya kinerja karyawan semakin baik. Hasil kinerja ini akan menentukan finansial benefit yang di dapat oleh karyawan yaitu bonus dan persentase kenaikan gaji. Struktur model akhir menunjukkan bahwa kinerja diukur dari persepsi karyawan terhadap hasil kerja yang mereka lakukan. Mereka mengukur hasil kinerja mereka sesuai dengan benchmark yang berlaku. Karyawan berasumsi kuantitas yang telah mereka kerjakan pun menjadi faktor persepsi mereka terhadap kinerja karyawan. Selain itu, efektivitas dalam bekerja menjadi faktor persepsi mereka juga dalam berasumsi mengenai kinerja mereka. 
Tabel 4. Hasil Model Struktural ${ }^{\mathrm{a}}$

\begin{tabular}{|c|c|c|c|c|}
\hline Hubungan antar variabel & $\begin{array}{l}\text { Koefisien } \\
\text { jalur }\end{array}$ & |t-hit| & Hasil & Kesimpulan \\
\hline $\begin{array}{l}\text { H1. Turnover intention berpengaruh } \\
\text { negatif terhadap Kinerja Karyawan }\end{array}$ & $-0,10$ & 1,93 & $\begin{array}{c}\text { Tidak } \\
\text { Signifikan }\end{array}$ & H1 ditolak \\
\hline $\begin{array}{l}\text { H2. Turnover intention berpengaruh } \\
\text { negative terhadap Komitmen organisasi }\end{array}$ & $-0,18$ & 1,40 & $\begin{array}{l}\text { Tidak } \\
\text { Signifikan }\end{array}$ & H2 ditolak \\
\hline $\begin{array}{l}\text { H3. Komitmen organisasi berpengaruh } \\
\text { negative terhadap Kinerja Karyawan }\end{array}$ & 0,73 & 15,62 & Signifikan & H3 diterima \\
\hline
\end{tabular}

${ }^{a}$ Data berdasarkan hasil dari running SEM PLS

Hasil uji hipotesis model struktural menunjukkan terdapat dua hipotesis yang ditolak yaitu $\mathrm{H} 1$ dan $\mathrm{H} 2$. Hubungan TI dengan K tidak signifikan (nilai T-statistiknya sama dengan 1,40 lebih kecil dari t-tabel 1,96) artinya turnover intention tidak berpengaruh terhadap kinerja karyawan (Tabel 4). Hal ini bertolak belakang dengan hasil penelitian Andini (2006) bahwa komitmen berpengaruh negatif terhadap turnover intention. Fenomena ini justru menarik karena ternyata tidak semua perusahaan yang yang memiliki turnover intention karyawan tinggi mengakibatkan kinerja karyawannya rendah. Mereka justru cenderung memiliki kinerja yang tinggi, karena mereka ingin mendapatkan rekomendasi dan pencapaian yang baik dari perusahaan sebelumnya sehingga membuat mereka memiliki nilai jual yang lebih tinggi.

Hubungan TI dengan E adalah tidak signifikan (nilai T-statistiknya sama dengan 1,93 lebih kecil dari t-tabel 1,96) artinya turnover intention tidak memiliki pengaruh terhadap komitmen organisasi terhadap perusahaan. Fenomena ini menarik seperti halnya hubungan turnover intention dan kinerja karyawan. Mereka yang ingin keluar dari perusahaan ini justru merasa memiliki komitmen yang tinggi. Hal ini bisa jadi karena mereka yang ingin keluar ingin mendapatkan kesan baik di perusahaan yang sekarang agar potensi untuk ditarik lagi menjadi karyawan perusahaan ini semakin besar dengan benefit yang jauh lebih besar di kemudian hari.

Hubungan $\mathrm{E}$ dengan $\mathrm{K}$ adalah signifikan (nilai T-statistiknya sama dengan 15,62 lebih besar dari t-tabel 1,96 ). Nilai original sampel positif yaitu sebesar 0,73 yang menandakan bahwa arah hubungan antara $\mathrm{E}$ dan $\mathrm{K}$ adalah positif. Hal ini sesuai dengan literatur yang menyebutkan bahwa komitmen sangat berpengaruh terhadap kinerja (Dessler 2009).

\section{KESIMPULAN}

Turnover intention tidak berpengaruh terhadap kinerja karyawan dan komitmen organisasi. Namun demikian, komitmen korganisasi memiliki pengaruh signifikan terhadap kinerja karyawan. Komitmen organisasi menjadi faktor penting dalam meningkatkan kinerja karyawan. Hal ini membuktikan bahwa perusahaan yang turnover intention karyawannya tinggi, tidak selalu beraikibat menurunkan komitmennya dan kinerjanya di perusahaan tempat bekerjanya sekarang. Perusahaan perlu memiliki strategi khusus untuk meningkatkan komitmen organisasi agar kinerja karyawan semakin meningkat.

Diperlukan penelitian lebih lanjut mengeksplorasi faktor-faktor yang dapat menurunkan turnover intention baik di perusahaan jasa maupun manufaktur. Selain itu juga disarankan sampel diperbanyak untuk memastikan apakah fenomena baru ini memang terjadi atau hanya sebatas variasi dari hasil penelitian saja.

Jurnal Manajemen dan Organisasi (JMO),

Vol. 9 No. 2 , Agustus 2018, Hal. $81-90$

\section{DAFTAR PUSTAKA}

Andini R. 2006. Analisis Pengaruh Kepuasan Gaji, Kepuasan Kerja, Komitmen Organisasional Terhadap Turnover Intention. Tesis. Undip

Allen NJ, Meyer JP. 1990. The Measurement and Antecedents of Affective, Continuance and Normative Commitment to the Organization. Journal of Occupational Psychology, 63, 118.

Dessler. (2009). Human Resources Management. Prentice Hall : New York.

Gea AA. 2014. Character Building Development Center, Binus University. Jakarta. 
Harnoto. 2002. Manajemen Sumber Daya Manusia (2nd ed.). Jakarta (ID): Prenhallindo.

Mangkunegara AP. 2000. Manajemen Sumber Daya Manusia. Bandung (ID): Remaja Rosdakarya

Mathis RL, Jackson JH. 2001. Manajemen Sumber Daya Manusia. Jakarta (ID): Salemba Empat. Robbins SP, Judge TA 2013. Organizational Behaviour (15 ed.). New York: Prentice Hall International

Sanusi A. 2014. Metodologi Penelitian Bisnis. Jakarta: Salemba Empat

Sugiyono. 2010. Metode Penelitian Pendidikan Pendekatan Kuantitatif, kualitatif, dan R\&D.

Bandung: Alfabeta 